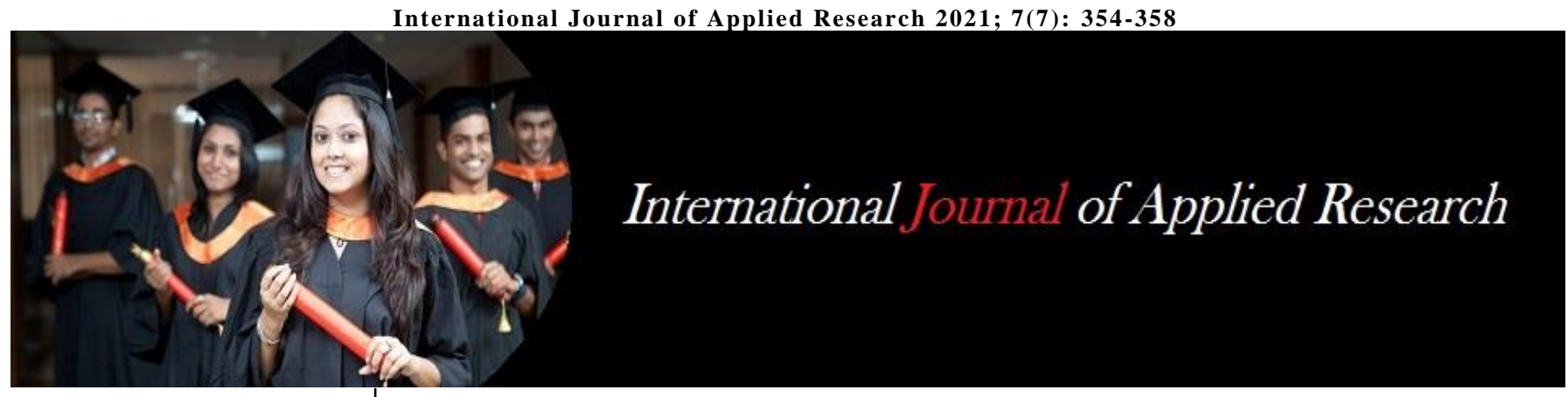

ISSN Print: 2394-7500 ISSN Online: 2394-5869 Impact Factor: 8.4 IJAR 2021; 7(7): 354-358 www.allresearchjournal.com Received: 25-05-2021 Accepted: 27-06-2021

\section{Shivani Raut}

Intern, PES Modern College of Physiotherapy, Pune,

Maharashtra, India

Dr. Sonal Patole Assistant Professor, PES Modern College of Physiotherapy, Pune, Maharashtra, India

Dr. Sucheta Golhar Principal, PES Modern College of Physiotherapy, Pune, Maharashtra, India
Corresponding Author: Shivani Raut Intern, PES Modern College of Physiotherapy, Pune, Maharashtra, India

\section{Correlation between scapular muscle endurance and handwriting legibility in school children: Correlational study}

\author{
Shivani Raut, Dr. Sonal Patole and Dr. Sucheta Golhar
}

DOI: https://doi.org/10.22271/allresearch.2021.v7.i7e.8805

\begin{abstract}
Purpose: Handwriting is an important functional task that needs to be performed by children in lower grades of elementary school, and it is an essential ability for academic achievements. To evaluate the ability of handwriting performance in children, various dimensions must be considered including the domain of handwriting, legibility, speed, and ergonomic factors. During the process of handwriting, most of the movements come from the forearm while the shoulder provides the power with minimum movement occurring at fingers and wrist. Muscular endurance is the ability of a muscle or muscle group to do repeated contractions against a less-than-maximum resistance for a given period. Fatigue of the Proximal muscles has been reportedly affected the coordination of Distal muscles. This study studies the correlation between scapular muscle endurance and handwriting legibility in school children.

Method: In this study, 70 samples were collected according to the inclusion and exclusion criteria. The test was explained to them and their parents in detail and ascent. Handwriting legibility was assessed using a handwriting legibility scale. Scapular muscle endurance was assessed using the Scapular muscle endurance test. Data was collected and analyzed.

Results: The results showed that there was a significant positive correlation between scapular muscle endurance and handwriting legibility. The statistical analysis showed that the correlation coefficient $(\mathrm{r}=0.5)$ which states that there is a moderately positive correlation. The $\mathrm{p}$-value was $<0.0001$ which is considered extremely significant.

Conclusion: This study concludes that there is a positive correlation between scapular muscle endurance and handwriting legibility.
\end{abstract}

Keywords: proximal, fine motor skills, functional task

\section{Introduction}

Handwriting is an important functional task that needs to be performed by children in lower grades of elementary school, and it is an essential ability for academic achievements. However, because the period in which children attempt handwriting varies according to the maturity of the nervous system, environmental experience, and the level of interest in letters, it is important to verify in the early stages of development whether children have problems in performing the task of handwriting. To evaluate the ability of handwriting performance in children, various dimensions must be considered including the domain of handwriting, legibility, speed, and ergonomic factors. Among these dimensions, legibility signifies the legibility of their handwriting. The factors that influence handwriting legibility include the shape of the letters, the size of the letters, the arrangement of the letters, and the amount of space between the letters. (Sang-Min Seo, 2017) ${ }^{[1]}$. According to previous studies which emphasize the importance of acquiring readiness skills before starting handwriting, there are various factors connected to the issues involved in this study. Among these factors, fine motor skills allow for the demonstration of good handwriting legibility through the ability to control a handwriting tool with speed and accuracy throughout activities such as fine motor precision, manual dexterity, and in-hand manipulation. As such, fine motor skills are essential for children before developing the repeated behavior of holding appropriate writing utensils. (Sang-Min Seo, 2017) ${ }^{[1]}$. 
Handwriting is a complex process which involves close coordination between musculoskeletal and nervous system. It is a complex, fine motor skill, where fine, precise, coordinated movements occur in the extremity. Many factors influence handwriting such as anatomy of extremity, general health, mental acuity, writing instrument, and surface. During the process of handwriting, most of the movements come from the forearm while the shoulder provides the power with minimum movement occurring at fingers and wrist (Kamalanathan*, 2017) ${ }^{[2]}$

Scapular muscles:

The strength and flexibility of the muscles and the overall posture of the writer affects the final output (M. J. M. Volman, 2006) ${ }^{[3]}$.

Strength training is a type of physical exercise specializing in the use of resistance to induce muscular contraction which builds the strength, anaerobic endurance, and size of skeletal muscle. The benefits of strengthening exercises are Increase in energy levels and a decrease in muscle fatigue level (M. J. M. Volman, 2006) ${ }^{[3]}$.

Proximal joints are generally responsible for the overall movement pattern of the arm, while distal joints primarily fine-tune movements to achieve the task goal. Occupational tasks may lead to fatigue of proximal muscles (e.g. overhead lifting), distal muscles (e.g. assembly tasks), or simultaneous proximal and distal fatigue (e.g. overhead assembly). During the process of handwriting, most of the movements come from the forearm while the shoulder provides the power with minimum movement occurring at fingers and wrist (Steve Graham, 1998) ${ }^{[4]}$.

Muscle activity of proximal parts is necessary for activation of distal parts. The stable activity of distal parts needs controlling the proximal parts. Thus, the stability of the shoulder girdle is required for the activity of distal parts such as fingers, wrists, and elbows (Kamalanathan*, 2017) [2].

Considering the kinetic chain perspective that emphasizes the extremities segments are related kinematically, it is assumed that even in hand neutral position (requiring no direct participation of shoulder), there is increased activity of major shoulder stabilizers during severe hand activity resulted from co-activation of proximal and distal muscle (Kamalanathan*, 2017) ${ }^{[2]}$.

Strength and endurance are important to enable children to perform everyday functions such as fine motor skills (e.g. holding a pencil appropriately, cleaning teeth), gross motor skills (e.g. carrying heavy school bags, walking, running, skipping, playground skills such as climbing, and sporting skills such as catching, throwing and hitting a ball with a bat) (Kamalanathan*, 2017) ${ }^{[2]}$.

The aim of this study was to find correlation between handwriting legibility and scapular muscle endurance in school children.

\section{Need of Study}

Handwriting plays a vital role in academic success since it's directly associated with the ability to express knowledge about different subjects.

- Thirty percent to $60 \%$ of the child's time is spent in fine motor activities, with writing as the predominant task.

- It continues to be an important life skill, in daily-life, as a variety of communication, archiving, expression of creativity and knowledge. Therefore, it's an important skill one should possess in today's context and it forms an integral a part of a student's life whether primary, secondary, or tertiary (Kamalanathan*, 2017) ${ }^{[6]}$.

- It can affect everything from completing written assignments to taking notes during lectures.

- When a student's handwriting isn't legible, it will be a struggle for the student and also the teacher.

- Slow handwriting or typing not only increases the time required to finish assignments, but it also changes the full nature of writing.

- When the tempo of writing is slowed way down or the writing is continually interrupted by the manual task, students never learn to flow through ideas and words (Kamalanathan*, 2017) ${ }^{[6]}$.

- Handwriting difficulties are commonly observed in children at primary schools (M. J. M. Volman, 2006) [10].

- Muscular endurance is your muscles' ability to perform repetitive motions - lengthening and contracting - over the long periods of your time without getting tired.

- The underlying purpose of muscular endurance is to improve performance. By improving your muscular endurance, you improve your muscles capabilities to support your daily activities.

\section{Aims}

- To find the correlation between scapular muscle endurance and handwriting legibility in school children.

\section{Objectives}

1. To assess scapular muscle endurance in school children using Scapular Muscle Endurance.

2. To assess handwriting legibility in school children using Handwriting Legibility Scale.

3. To assess correlation between scapular muscle endurance and handwriting.

\section{Review of Literature}

1. M. J. M. Volman, Brecht M. van Schendel,Marian J. Jongmans (jul-aug 2006) conducted a study Handwriting Difficulties in Primary School Children: A Search for Underlying Mechanisms Am J Occup Ther Jul-Aug 2006;60(4):451-60. doi: 10.5014/ajot.60.4.451. which concluded that Results suggest that two different mechanisms underlie the quality of handwriting in children with and without handwriting problems. Poor quality of handwriting of children with HWP seems particularly related to a deficiency in visual-motor integration.

2. Steve Graham a, Virginia Berninger b, Naomi Weintraub c \& William Schafer a, University of Maryland, University of Washington, Hebrew University of Jerusalem (apr 2010) conducted a study Scapular Muscle Performance in Individuals with Lateral Epicondylalgia J Orthop Sports Phys Ther. 2015 May;45(5):414-24.

Doi:10.2519/jospt.2015.5290.PMID: 25579691 which concluded that the development of handwriting speed and legibility in 900 children in Grades 1-9 was examined. The children's speed of handwriting on the copying task typically increased from one grade to the next, but the pace of development was uneven during the intermediate grades and leveled off in Grade 9 as speed began to approximate adult speeds. In contrast, improvement in handwriting legibility on the 3 writing 
tasks was primarily limited to the intermediate grades. Girls' handwriting was more legible than boys' handwriting, and the girls wrote faster in Grades 1, 6, and 7. Right-handers were also faster than left-handers, but there was no difference in the legibility of their written products. Finally, handwriting speed contributed significantly to the prediction of legibility on the narrative and expository writing tasks, but the contribution was small, accounting for only $1 \%$ of the variance.

3. Joseph M. Day, PT, PhD, OCS, CIMT; Heather Bush, $\mathrm{PhD}$; Arthur J. Nitz, PT, PhD, ECS, OCS ;Tim L. Uhl, ATC, PT, PhD, FNATA.(2015)conducted the study Scapular Muscle Performance in Individuals with Lateral Epicondylalgia; journal of orthopaedic \& sports physical therapy :10.2519/jospt.2015.5290 which concluded that when compared to a matched comparison group, there were impairments of 54 scapular musculature strength and endurance in patients with LE, suggesting that the scapular 55 musculature should be assessed and potentially treated in this population. Cause and effect cannot be established as the weakness of the scapular musculaturecould be a result of LE.

4. P Kamalanathan*, ShabreenBanu H (june 2017) conducted the research Effects of Upper Limb Strengthening Exercises on Handwriting Speed in Undergraduate Students. International Journal of Pharmaceutical and Clinical Research 2017; 9(6): 475479 doi: 10.25258/ijpcr.v9i6.8778 Conclusion: -Upper limb strengthening exercise programmes can be used to improve the handwriting speed.

5. Anna L. Barnetta, Mellissa Pruntyb, Sara Rosenblum (Nov 2017) Development of the Handwriting Legibility Scale (HLS): A preliminary examination of Reliability and Validity. Conclusions: The overall findings suggest that the HLS may be a useful tool to identify poor handwriting legibility, with application across different languages and writing script.

6. Sang-Min Seo, MS, OT, Department of Occupational Therapy, Seoul Metropolitan Children's Hospital: 260 Heungneungno,Naegok-dong, Seocho-gu, Seoul 06801, Republic of Korea (Nov 2017)conducted a research to study The effect of fine motor skills on handwriting legibility in preschool age children. 30(2):324-327. doi: 10.1589/jpts.30.324. Epub 2018 Feb 28.PMID: 295457 which concluded Through the current research, occupational therapists can provide activities that aid the development of fine motor precision and in-hand manipulation skills for children during the instruction and treatment of handwriting to preschool age children, which helps to conduct better legibility in their handwriting.

7. S Jeffrey C. Cowley, Deanna H. Gates(2017) conducted a research to study Proximal and distal muscle fatigue differentially affect movement coordination. PMCID: PMC5325574

DOI: 10.1371/journal.pone.0172835 which concluded This study identified significant movement changes in trunk, shoulder, and elbow kinematics after proximal muscle fatigue in a repetitive, timed movement task. In contrast, after distal muscle fatigue, there were changes mainly in wrist and hand movement. Kinematic variability increased at proximal but not distal joints after both proximal and distal fatigue. These findings agree with previous research during disc throwing, and provide external validity to the idea that fatigue adaptations are governed by hierarchical control principles. Furthermore, these results underscore the importance of considering the localization of muscle fatigue in order to assess the contributions of fatigue to injury risk. Further research is needed to understand how people modify the variability of different joints during fatigue and determine how consistent these changes are across tasks.

\section{Methodology}

- Sample Size: 70

- Study Setting: Societies in and around city.

- Study Design: Correlational study.

- Sampling Method: Convenient Sampling.

- Study Population: School children.

- Study Duration: 6 months.

\section{Criteria}

- Inclusion Criteria

- School going Male and Female children (M. J. M. Volman, 2006) ${ }^{[10]}$

- Student of age group between 9 to 11 years of age (Steve Graham, 1998) ${ }^{[5]}$.

\section{- Exclusion Criteria}

- Recent fractures - fracture of the assessing upper limb within 6 months.

- Dyslexia.

- Dysgraphia.

- Nerve injury of the dominant upper limb.

- Scapular dyskinesis.

- Dyspraxia

\section{Materials and Tools}

Ascent form

Pen

Paper

Weighing scale

Weight cuffs

Stopwatch

\section{Outcome Measures}

\subsection{Handwriting Legibility Scale (HLS)}

Reliability $=0.92$

Validity $=0.75$

- The HLS is a non-language dependent scale which assesses global legibility, based on five criteria applied to samples of 'free writing' (Anna L. Barnetta, 2018) ${ }^{[2]}$.

- The HLS may be a useful tool to identify poor handwriting legibility, with application across different languages and writing scripts.

- Procedure: the subjects were explained about the procedure and were provided with papers and pencils.

- They were given a printed paragraph of about 10 lines and were asked to copy it.

\subsection{Scapular Muscle Endurance Test}

It is a commonly used test to assess scapular muscle endurance.

- Pre-test: The test procedure was explained to the subjects. 
- Basic information such as age, grade, Body weight were recorded.

- Materials required: weight cuffs, stop watch.

- Procedure: Participant was positioned in prone lying with testing arm at edge of table.

The testing arm was passively abducted to $135^{\circ}$.

Weight cuff of $1 \%$ of Patients body weight was tied to proximal humerus. Participants were asked Retract scapula and hold the position in the plane of thorax. Test was stopped when the participant protracted shoulder and was no longer able to hold the position (Joseph M Day 1, 2015) ${ }^{[4]}$.

- Scoring: The test was stopped when the subject protracted the shoulder or found it difficult to hold the position. The total number of seconds the subject was able to hold the position effortlessly was recorded and documented.

\section{Procedure}

- The study started with synopsis presentation to an ethical committee of P.E.S Modern College of Physiotherapy.

- Ethical clearance was obtained from the ethical committee

- Various societies were visited in and around city

- Subjects were selected based on their inclusion and exclusion criteria

- A written consent was taken from the parents of the subjects and the subjects will be explained about the procedure.

- Handwriting Legibility was assessed using Handwriting Legibility Scale.

- Scapular muscle endurance was assessed using Scapular Muscle Endurance Test (Joseph M Day 1, 2015) ${ }^{[4]}$.

- The data was entered in excel spread sheet, tabulated and subjected to Statistical analysis.

\section{Data Analysis}

- Handwriting legibility was assessed using Handwriting Legibility Scale.

- Scapular Muscle endurance was assessed using Scapular muscle endurance test.

- The data was entered in excel spread sheet, tabulated and subjected to statistical analysis.

- The data entered was analysed with the help of IBM SPSS software and graphpad Instat to check correlation between Scapular muscle endurance and handwriting legibility.

Table 1: Age wise distribution of samples.

\begin{tabular}{|c|c|}
\hline Age In Years & Total Number \\
\hline 9 & 17 \\
\hline 10 & 9 \\
\hline 11 & 44 \\
\hline
\end{tabular}

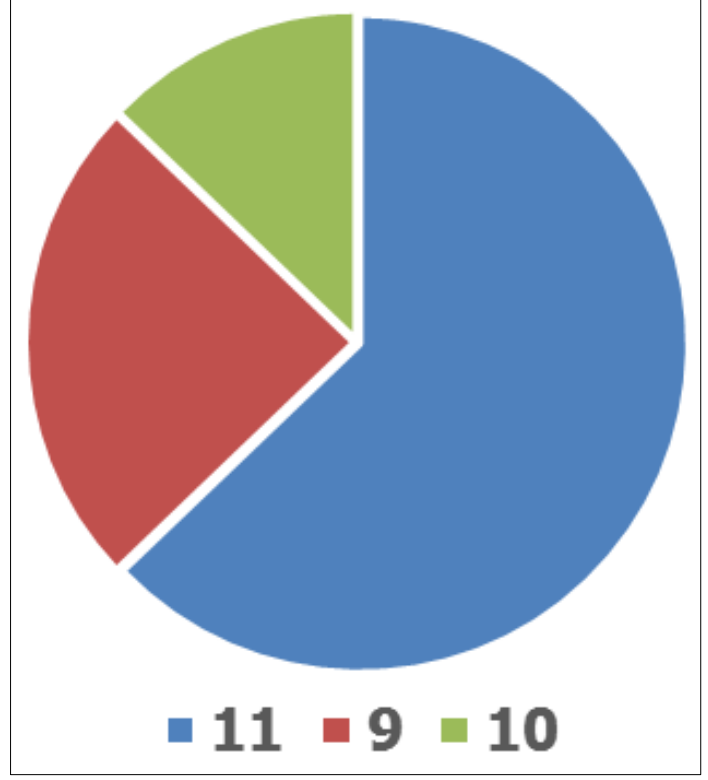

Fig 1: Age wise distribution of samples

\section{Statistical Analysis}

- Statistical analysis was done using the outcome measure handwriting legibility score and scapular muscle endurance.

- Analysis was done using Pearson correlation test by using Instat 3.10 software and IBM SPSS.

Table 2: Mean Value and Standard deviation of Outcome measure

\begin{tabular}{|c|c|c|}
\hline Outcome Measure & Mean Value & Standard Deviation \\
\hline SMET & 10.09 & 3.14 \\
\hline HLS & 0.10 & 0.051 \\
\hline
\end{tabular}

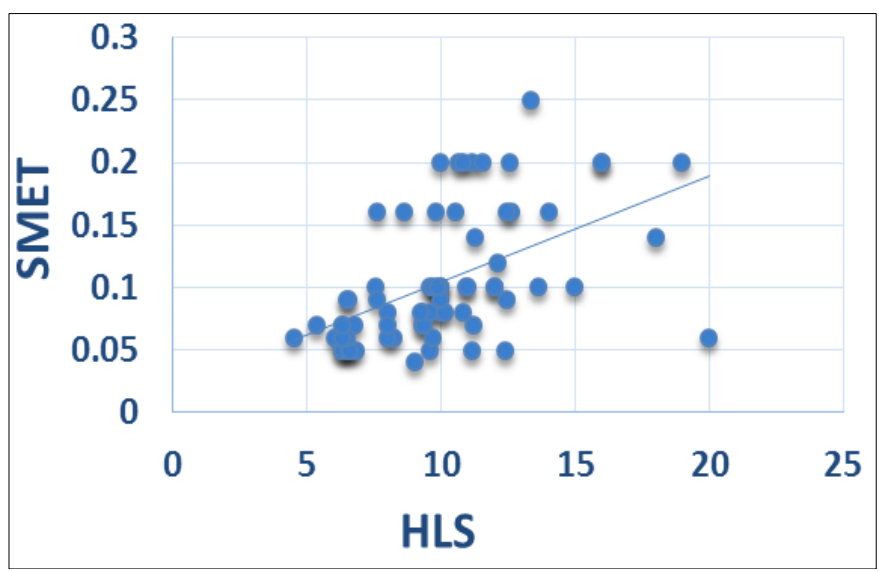

Fig 2: Scatterplot of Scapular muscle Endurance and Handwriting legibility

Table 3: $P$ value and ' $r$ ' value

\begin{tabular}{|c|c|c|}
\hline P Value & 'r' value & significance \\
\hline$<0.0001$ & 0.5 & Considered extremely significant \\
\hline
\end{tabular}




\section{Results}

- The following study was conducted to check the correlation between scapular muscle endurance and handwriting legibility in school children.

- The values of handwriting legibility score and scapular muscle endurance were correlated using GraphPad Instat.

- The mean values for scapular muscle endurance and handwriting legibility were 10.09 and 0.10 respectively.

- The statistical analysis shows the correlation coefficient $\mathrm{r}$ is 0.5 which states that there is moderately positive relationship.

- The statistical analysis shows that the $\mathrm{p}$ value is $<0.0001$ which is extremely significant hence there is positive correlation between scapular muscle endurance and handwriting legibility.

\section{Discussion}

- The following study was done to assess the correlation between scapular muscle endurance and handwriting legibility assessed by using SMET and HLS respectively in school children.

- In this study total 70 subjects were included(both males and females) in the age group od 9 to 11 years.

- A statistically significant correlation was seen between scapular muscle endurance test score and handwriting legibility score. It was seen that as the individuals scapular muscle endurance score increased the legibility improved as well.

- The strength of this association between scapular muscle endurance and handwriting legibility was fair.

- Gesell, et all (1947) approves the fact that as Motor development codes, none of the fine motor skills can develop smoothly without the concurrent development of gross motor (large muscle) skills. In fact, typically, development proceeds in a cephalo-caudal (head to toe) and proximal-distal (moving from the body parts closest to the trunk to those furthest away pattern.

- So, in simple terms, development of stable shoulders and upper arms provides a solid base for development of skills using writing tools.

- Shoshana Naider -Steinhart, et all (2007) in their study Analysis of Proximal and Distal Muscle Activity During Handwriting Tasks concluded that the proximal muscle functions as a stabilizer during a handwriting task.

- The above study was supported by Margaret Wallen et al., (1998) who used intervention that targeted primarily at improving the proximal muscle stabilization of the upper extremity. This is supported by the proximal distal muscle principle it states that "Proximal Muscle Stability is a pre-requisite for manipulative hand use. ${ }^{[11]}$

- O. Alizadehkhaiyat et al. (2011) conducted a study on 16 healthy subjects ( 9 male and 7 female) to study the Activity and fatigue of the shoulder muscles in a controlled hand grip they used Electromyography of scapulothoracic muscles during grip task the results showed that grip increases the activity of both muscles [1].

- The above studies support our finding which showed that the muscle endurance and handwriting legibility are related.

- In Upper extremities tasks, the energy development and output follows a proximal to distal sequencing known as the kinetic chain. Changes in various segments can affect the function of distal component to a significant extent.

- Scapular muscles act as stabilizers for the glenohumeral stability.

- As the muscle endurance decreases there is more rapid development of fatigue which can cause change in movement pattern.

- Scapular muscle fatigue has shown to produce alterations in the kinematics of the extremities i.e less scapular muscle endurance can affect distal functioning.

- So by above mechanism scapular endurance can affect handwriting legibility.

\section{Conclusion}

This study concludes that there is a positive correlation between scapular muscle endurance and handwriting legibility in school children.

\section{References}

1. Alizadehkhaiyat $\mathrm{O}$, Fisher AC, Kemp GJ, Vishwanathan K, Frostick SP. Shoulder muscle activation and fatigue during a controlled forceful hand grip task. Journal of Electromyography and Kinesiology 2011;21(3):478-82.

2. Barnett AL, Prunty M, Rosenblum S. Development of the Handwriting Legibility Scale (HLS): A preliminary examination of Reliability and Validity. Research in developmental disabilities 2018;72:240-7.

3. Cowley JC, Gates DH. Proximal and distal muscle fatigue differentially affect movement coordination. PloS one 2017;12(2):e0172835.

4. Day JM, Bush H, Nitz AJ, Uhl TL. Scapular muscle performance in individuals with lateral epicondylalgia. journal of orthopaedic \& sports physical therapy 2015;45(5):414-24.

5. Graham S, Berninger V, Weintraub N, Schafer W. Development of handwriting speed and legibility in grades 1-9. The Journal of Educational Research 1998;92(1):42-52.

6. Kamalanathan P. Effects of upper limb strengthening exercises on handwriting speed in undergraduate students. International journal of pharmaceutical and clinical research 2017;9(06):475-9.

7. Naider-Steinhart S, Katz-Leurer M. Analysis of proximal and distal muscle activity during handwriting tasks. American Journal of Occupational Therapy 2007;61(4):392-8.

8. Nakhaie N, Nodehi-Moghadam A, Bakhshi E, Goghatin Alibazi R. Activation of shoulder girdle muscles during gripping task: a systematic review of literature. Physical Treatments-Specific Physical Therapy Journal 2014;4(1):3-8.

9. Seo SM. The effect of fine motor skills on handwriting legibility in preschool age children. Journal of physical therapy science 2018;30(2):324-7.

10. Volman MJ, van Schendel BM, Jongmans MJ. Handwriting difficulties in primary school children: A search for underlying mechanisms. American Journal of Occupational Therapy 2006;60(4):451-60.

11. Wallen M, Bonney MA, Lennox L. Interrater reliability of the handwriting speed test. The Occupational Therapy Journal of Research 1997;17(4):280-7. 